\title{
The Inhibition of Cell Proliferation Using Silencing of N-Cadherin Gene by siRNA Process in Human Melanoma Cell Lines
}

\author{
D. Ciołczyk-Wierzbicka*, D. Gil and P. Laidler \\ Chair of Medical Biochemistry Jagiellonian University Medical College, Kraków, ul. Kopernika 7, 31-034 Kraków, Poland
}

\begin{abstract}
Malignant melanoma is a disease with high mortality rate caused by rapid metastasis. Cell motility is physically and biochemically restricted by cadherin-mediated cell interactions and signalling pathways, and alterations in cadherin expression strongly correlate with $\mathrm{E}$ to $\mathrm{N}$-cadherin switch as well as the metastasis and progression of tumours. Contrary to E-cadherin, $\mathrm{N}$-cadherin plays an important role in stimulating processes of cell division, migration, differentiation and death.
\end{abstract}

In this study we investigated the role of N-cadherin in proliferation and AKT, ERK, beta-catenin signalling pathway in human melanoma cells: WM793(VGP), WM115(VGP) from the primary tumor site, as well as Lu1205(lung) and WM266-4(skin) from metastatic sites.

$\mathrm{N}$-cadherin, pAKT(S473), $\beta$-catenin, pERK1/2(T202/Y204), cyclin D1, cyclin D3, cyclin-dependent kinases CDK4, CDK6, and p15, p16, p21, p27 inhibitors expression was determined by western blot analysis. The study on proliferation of cells was performed with the use of BrdU incorporation and crystal violet staining assays.

Knock-out of N-cadherin gene expression by siRNA process reduced the expression of: pAKT(S473), pERK1/2(T202/Y204), betacatenin, cyclin D1, cyclin D3 , cyclin-dependent kinases CDK4, CDK6 while increasing expression of cell cycle inhibitors p21 and p27, and significantly decreased cell proliferation (50-70\%). The collected data indicate that $\mathrm{N}$-cadherin mediates the effect of cell cycle in G1 phase by AKT, $\beta$-catenin, and ERK signalling pathway.

These results suggest that increased expression of N-cadherin significantly contributes to the increased invasive potential of melanoma cells. Silencing of N-cadherin arrests cell growth at G1 phase and inhibits the entry into S-phase which is of great importance as to its possible future use in cancer treatment.

Keywords: AKT, $\beta$-catenin, cell cycle, ERK, melanoma, N-cadherin, proliferation, siRNA.

\section{INTRODUCTION}

Malignant melanoma is the most aggressive, therapy resistant and deadly form of skin cancer. It arises from malignant transformation of melanocytes, the pigmented skin cells. During the process of malignant transformation the nascent melanoma cells acquire the ability to proliferate indefinitely and escape from their local microenvironment. Microenvironmental escape is mediated through altered expression of cell-cell, cell-matrix adhesion proteins, among others.

Cadherins are transmembrane glycoproteins that provide strong intercellular adhesion in $\mathrm{Ca}^{2+}$ dependent manner. Classic cadherins are a transmembrane component of cellular junctions. They are composed of three segments: large extracellular domain, which mediates homophilic type cell adhesion, a transmembrane domain, and a highly conserved cytoplasmic domain that interacts with catenins to link cadherins to the actin cytoskeleton. Cadherins play a major role in epithelial cell-cell adhesion [1-2].

Expression of $\mathrm{N}$-cadherin has been reported in a variety of normal tissues including neuronal, endothelial and muscle cells and subpopulation of early haematopoietic progenitor cells [3]. In embryogenesis $\mathrm{N}$-cadherin is the key molecule during gastrulation and neural crest development. It also regulates cell-surface adhesion through homotypic adhesion with the same cadherin species [3].

Normally cultured human melanocytes express both E-cadherin and P-cadherin. E-cadherin is primarily responsible for adhesion of melanocytes to keratinocytes [4-6]. Melanocytes embedded in the epidermis among the basal layer interact with keratinocytes through E-cadherin, which in effect regulates their growth.

$\mathrm{N}$-cadherin heavily glycosylated protein [7-8] is another classic cadherin expressed in human skin by dermal fibroblasts and vascular endothelial cells, but not by keratinocytes or melanocytes.

Malignant transformation of melanocytes is frequently accompanied by loss of E-cadherin expression, and induction of

*Address correspondence to this author at the Chair of Medical Biochemistry Jagiellonian University Medical College, Kraków, ul. Kopernika 7, 31-034 Kraków, Poland; Tel: +4812 42274 00; Fax: +4812 42232 72; E-mail: mbciolcz@cyf-kr.edu.pl expression of mesenchymal molecules like $\mathrm{N}$-cadherin. Normal melanocytes and the surrounding keratinocytes express E-cadherin to stable tissue assembly [9]. E-cadherin functions as an invasion suppressor and is down-regulated in most cancer, while $\mathrm{N}$-cadherin is frequently up-regulated. H-cadherin and P-cadherin, just as Ecadherin, reduce melanoma cell growth and invasion, but their expression decreases or disappears in malignant melanoma [10-11].

Recent literature data [12] suggest that during malignant transformation the extent of tumor cell invasion $\mathrm{N}$-cadherin undergoes proteolytic processing altered, as a result of which an abundant amount of nonadhesive precursor $\mathrm{N}$-cadherin (pro- $\mathrm{N}$ cadherin) is formed at the cell surface, although total N-cadherin levels remain constant. Pro-N-cadherin promotes cell migration and invasion in vitro.

Expression of $\mathrm{N}$-cadherin in epithelial cells induces changes in morphology of a fibroblastic phenotype, rendering the cells more motile and invasive.

$\mathrm{N}$-cadherin becomes more prevalent as tumours become more malignant and aggressive. $\mathrm{N}$-cadherin expressed in melanoma cells not only mediates cell-cell interactions between adjacent cancer cells and stromal fibroblasts, as well as endothelial cells, but also promotes survival and migration of melanoma cells [2]. It is expressed by several human fetal tissues and re-expressed by the corresponding neoplasm, thus contributing to melanoma invasive phenotype $[7,4]$.

$\mathrm{N}$-cadherin role in cell differentiation, transformation, and invasion has also been documented [13-16] with some of these functions, most probably depending upon the activation of intracellular signal transduction cascades [17-19]. However, the mechanism by which $\mathrm{N}$-cadherin regulates entry into the cell cycle has not been fully elucidated.

The key to successful cancer treatment is learning signalling hubs in the network-associated melanoma cells with proliferation and survival. Many attempts have been made to assess the rate of tumor proliferation using various biological markers, including mitotic rate, cyclins, and cyclin-dependent kinase inhibitors such as p15, p16, p21 and p27. Entry into the S-phase of cell cycle, critical 
for future cell division, is regulated at the G1 restriction checkpoint, a process that becomes deregulated in cancer cells. Progression through the G1 into S-phase of the cell cycle is driven by cyclin dependent kinases (CDK) 4 and 6 which interact with cyclin D1 and D3, as well as by CDK2 which interacts with cyclins A/E [20].

In this study, we examined if and how $\mathrm{N}$-cadherin might regulate melanoma cell proliferation by the control of cell cycle at G1 point. We studied the affect of N-cadherin using its siRNAmediated knock-down to levels of pAkt, ERK1/2, $\beta$-catenin, cell cycle protein and proliferation.

\section{MATERIALS AND METHODS}

\section{Cell Culture}

Human melanoma cell lines WM793 (VGP) -Lu1205 (metastatic, lung) and WM115 (VGP) - WM266-4 (metastatic, skin) were cultured in RPMI-1640 medium supplemented with $10 \%$ fetal bovine serum and penicillin/streptomycin. Cells were treated with PI3K inhibitor - LY294002 (Cell Signalling TM) in $20 \mu \mathrm{M}$ concentration for $24 \mathrm{~h}$ and ERK1/2 inhibitor - U0126 (Cell Signalling TM) in $10 \mu \mathrm{M}$ concentration for $2 \mathrm{~h}$. Cells were obtained from the ESTDAB Melanoma Cell Bank (Tubingen, Germany).

\section{SiRNA}

Two $21 \mathrm{bp}$ double-stranded siRNA $\mathrm{CDH} 2$ molecules specifically targeting for the N-cadherin: siRNA $\mathrm{CDH} 2 \# 1$ created by in vitro transcription (Silencer TM siRNA Construction Kit (Ambion) and commercially available siRNA CDH2\#2 (Ambion ID\# S27773). Small interfering RNA (siRNA) against the $C D H 2 \# 1$ target sequence 5'-AAAGTGGCAAGTGGCAGTAAA-3' (nucleotides 798-818; NM001792) was used. Effect of RNA interference on expression of $\mathrm{CDH} 2$ mRNA and protein was determined by reverse transcription-PCR (RT-PCR) and Western immunoblotting respectively. Glyceraldehyde-3-phosphate dehydrogenase (GAPDH) was used as an internal control to monitor efficiency of RT-PCR.

\section{siRNA Transfection}

Melanoma cells were grown until $60 \%$ confluence and then transfected using Oligofectamine reagent (Invitrogen) according to the manufacturer's protocol with two different, $21 \mathrm{bp}$ doublestranded siRNA molecules specifically targeting for the N-cadherin: siRNA $\mathrm{CDH} 2$ - in vitro transcription (SilencerTM siRNA Construction Kit (Ambion)) and commercially available (Ambion ID\#S27773) or a control nonsilencing sequence (Ambion). WM793, WM115, WM266-4 cells were transfected with $50 \mathrm{nM}$ and Lu1205 cells with $100 \mathrm{nM}$ siRNA. Medium was replaced 24h later with a fresh one and cells were grown for an additional $24 \mathrm{~h}$ to $48 \mathrm{~h}$ period ( $48 \mathrm{~h}$ or $72 \mathrm{~h}$ post-tansfection) prior to further analysis.

\section{Gel Electrophoresis}

Gels were prepared in the presence of SDS in reducing conditions. Cell lysates containing equal amounts of protein were loaded per well and separated with the use $4.5 \%$ stacking and $10 \%$ (or $12 \%$ ) separation gel in a $4 \mathrm{~h}$ run.

\section{Western Blotting}

Proteins were transferred onto PVDF membrane overnight using a Trans-Blot Electrophoretic Transfer Cell (Bio-Rad) at 150 $\mathrm{mA}$ in $25 \mathrm{mM}$ Tris, $192 \mathrm{mM}$ glycine, $20 \%$ methanol buffer at $\mathrm{pH}$ 8.4. Antibodies used for probing Western blots were: anti-Ncadherin, pERK1/2 (T202/Y204), ERK, $\beta$-catenin (all Transduction Laboratories, BD), phospho- $\beta$-catenin (S33/37/T41), phospho- $\beta$ catenin (S552), phospho- $\beta$-catenin (S675), AKT, phospho-AKT
(S473), p15, p16, p21, p27, cyclin D1, cyclin D3, CDK4 kinase, CDK6 kinase, phospho- GSK-3 $\beta$ (S9), phospho-GSK-3 $\beta$ (Y216) (all Cell Signalling Technology), and $\beta$-actin (Sigma). Bands were visualized using alkaline phosphate coupled with secondary antimouse or anti-rabbit antibody (Sigma). Finally, immunoreactions were visualized by NBT/BCIP staining (Roche).

\section{Cell Proliferation Assay}

The proliferation of cells was assessed with the BrdU ELISA and crystal staining violet tests. The cells were plated at density $5 \times 10^{3}$ cell/well for WM793 or WM115, and $3 \times 10^{3}$ for Lu1205 or WM266-4 in 96 well plates. The cells were transfected with $\mathrm{N}$ cadherin siRNA and after a period of $24 \mathrm{~h}$ medium was replaced with a fresh one. Proliferation assays were performed with conventional methods BrdU ELISA test (Roche) according to the manufacturer's protocol. For the crystal violet test, cells were cultured for $48 \mathrm{~h}$ or $72 \mathrm{~h}$ at $37^{\circ} \mathrm{C}$, afterwards medium was removed and cells were washed with PBS. Thereupon, cells were fixed with $200 \mu 196 \%$ ethanol for $15 \mathrm{~min}$, stained with $0.5 \%$ crystal violet, washed with water and air dried. After subsequent $30 \mathrm{~min}$ incubation of cells with elution solution $\left(1: 10.1 \mathrm{M} \mathrm{Na}^{+}\right.$citrate, $\mathrm{pH}$ 4.2 to $100 \%$ ethanol $200 \mu \mathrm{l}$ per well), samples were measured at $540 \mathrm{~nm}$ on a plate reader (BIO-TEK).

\section{Cytotoxicity Assay}

The cytotoxicity of N-cadherin siRNA (100 nM), PI3K inhibitor - LY294002 $(20 \mu \mathrm{M})$ ERK1/2 inhibitor - U0126 $(10 \mu \mathrm{M})$ was assayed by determination of activity of lactate dehydrogenase (LDH) released by treated cells to medium (Cytotoxicity Detection Kit LDH, Roche, Germany). N-cadherin siRNA, LY294002 and U0126 inhibitor, showed no cytotoxicity effect in the course of $72 \mathrm{~h}$ treatment of all melanoma cells as LDH activity in examined media never exceeded $3 \%$ of total LDH activity.

\section{Statistics}

Cell proliferation data were calculated from mean values of replicate experiments as indicated, using the Student's t-test. Results were considered significant at $\mathrm{p}<0.05$.

\section{Densitometry Analysis}

Densitometry analysis of $\mathrm{N}$-cadherin bound expression at the protein and mRNA level was performed on volume (sum of intensities bound) using UVIMAP V.99.03 software (UVItec St John's Innovation Centr Cowley Road Cambridge CB4 OWSEngland).

\section{RESULTS}

\section{N-Cadherin Silencing by siRNA}

Melanoma cell lines: WM793, WM115 from VGP and Lu1205, and WM266-4 metastatic all express N-cadherin, but no E- and Pcadherin, as was established on both on mRNA and protein levels. The gain of $\mathrm{N}$-cadherin expression in melanoma has proved to be important in terms of its effect on cell migration, invasion, proliferation and survival. Two sequences of siRNA molecules specifically targeting for the N-cadherin: siRNACDH2\#1designed by in vitro transcription (Silencer TM siRNA Construction Kit (Ambion)) and (ID\#S27773) siRNACDH2\#2 designed commercially efficiently reduced $\mathrm{N}$-cadherin expressions (Fig. 1). The results of densitometry comparison of $\mathrm{N}$-cadherin expression at the protein and mRNA level after knock-down of N-cadherin are presented in Table $\mathbf{1}$.

Re-expression of E-cadherin on mRNA or protein level upon silencing of N-cadherin was not observed. 


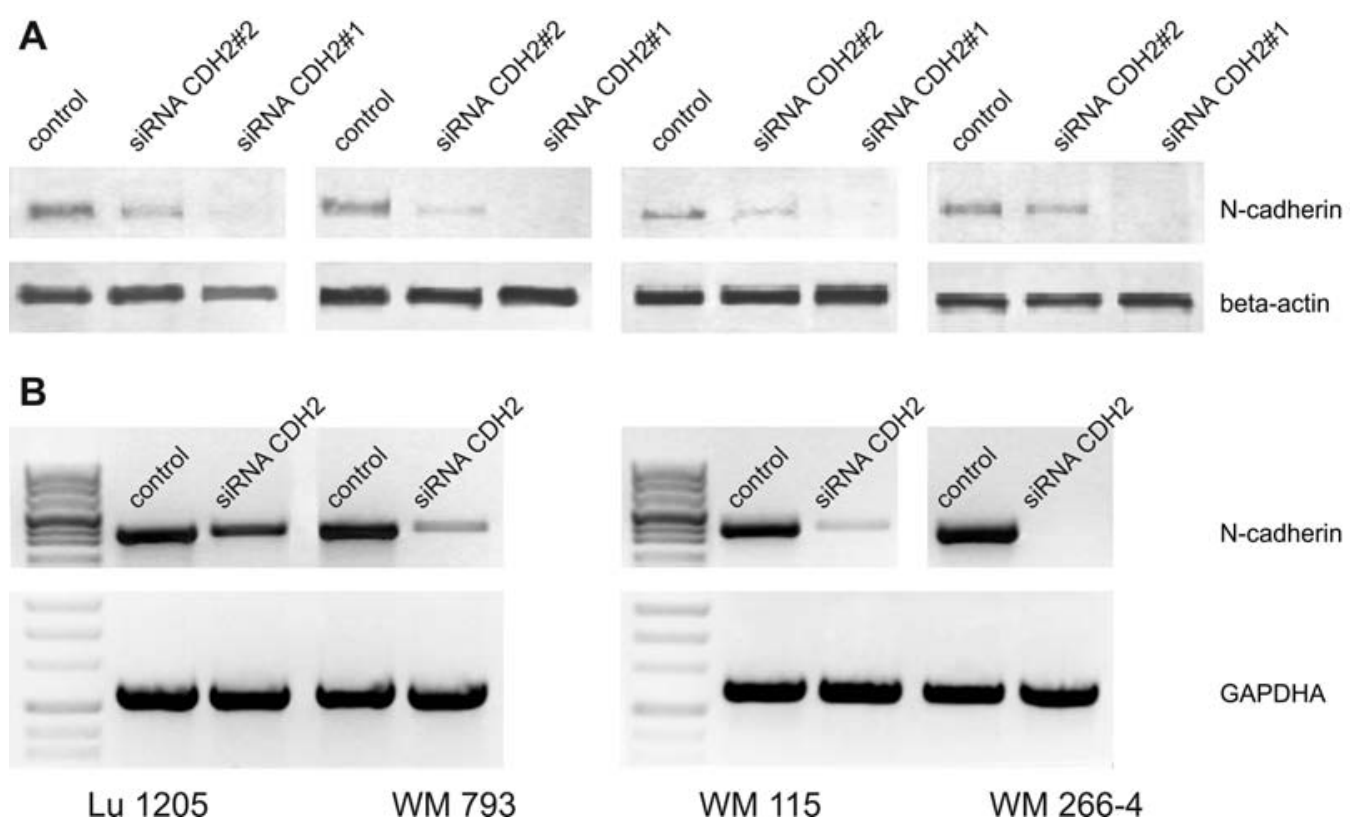

Fig. (1). N-cadherin silencing by siRNA. Effects of RNA interference on (A) protein level, western immunoblotting and (B) expression of mRNA were determined by reverse transcription-PCR (RT-PCR) $48 \mathrm{~h}$ after transfection.

Table 1. The Densitometry Analysis of N-Cadherin Expression at the Protein and mRNA Level After Knock-Down of N-Cadherin

\begin{tabular}{|c|c|c|c|c|}
\hline & \multicolumn{5}{|c|}{ Volume -intensities of bound/ percent of control } \\
\hline Cell line & Lu1205 & WM793 & WM115 & WM266-4 \\
\hline \hline \multicolumn{5}{|c|}{ Protein level } \\
\hline control & $13060(100 \%)$ & $16935(100 \%)$ & $13452(100 \%)$ & $10794(100 \%)$ \\
\hline siRNACDH2\#2 & $6143(47 \%)$ & $2542(15 \%)$ & $5014(37)$ & $8137(75 \%)$ \\
\hline siRNA CDH2\#1 & $917(7 \%)$ & $1774(10 \%)$ & $679(5 \%)$ & $929(8,6 \%)$ \\
\hline \multicolumn{5}{|c|}{ mRNA level } \\
\hline control & $28203(100 \%)$ & $27033(100 \%)$ & $29012(100 \%)$ & $31396(100 \%)$ \\
\hline siRNACDH2 & $12507(44 \%)$ & $2917(9,2 \%)$ & $171(0,5 \%)$ & $1789(5,6 \%)$ \\
\hline
\end{tabular}

\section{siRNA-Mediated Knock-Down of N-Cadherin Results in the Decrease of AKT Kinase Activity}

Cadherin-directed cell adhesion plays a key role in the maintenance of membrane cell signalling, including PI3K/AKT [21]. Wnt and AKT are the most important signalling pathways involved in cell proliferation (growth).

AKT kinase is activated by phosphorylation at two sites: T308 in the kinase domain, and S473 in the regulatory tail. Expression of activated AKT was assessed by immunoblotting cell lysates using phospho-specific antibodies against phosphorylated S473. To study the effect of $\mathrm{N}$-cadherin silencing on the AKT pathway, PI3 kinase inhibitor - LY294002 $(20 \mu \mathrm{M})$ was used as a positive control.

The results indicate that $\mathrm{N}$-cadherin knock-down with $\mathrm{CDH} 2$ leads to a reduced level of S473 phospho AKT leaving total AKT expression unchanged (Fig. 2A). Melanoma cells treated with PIK3 kinase inhibitor -LY294002 showed reduced pAkt level as in case of $\mathrm{CDH} 2$ siRNA, but did not alter N-cadherin level (Fig. 2A).

siRNA-Mediated Knock-Down of $\mathrm{N}$-Cadherin Results in the Decrease of pERK1/2 Kinase Activity

The MEK-ERK1/2 signalling pathway is known to regulate diverse cellular processes such as proliferation, survival, differentiation, motility and invasion [22]. Expression of ERK and pERK1/2 was assessed by immunoblotting cell lysates with phospho-specific antibodies against phosphorylated T202/Y204. To study the effect of $\mathrm{N}$-cadherin silencing on the ERK pathway, ERK1/2 kinase inhibitor - U0126 $(10 \mu \mathrm{M})$ was used as positive control.

The decrease of the expression of ERK1/2 in melanoma cell lines after knock-down N-cadherin clearly indicates the effect of $\mathrm{N}$ cadherin on the ERK pathway. There was no change in the expression of total ERK (Fig. 2B). The treated melanoma cells with ERK1/2 kinase inhibitors - U0126 showed reduced level of pERK1/2 as in case of $C D H 2$ siRNA, but did not influence the total level of $\mathrm{N}$-cadherin (Fig. 2B).

\section{N-Cadherin Regulates the Level of $\beta$-Catenin}

The role of $\mathrm{Wnt} / \beta$-catenin pathway is to regulate cytosolic $\beta$ catenin protein level via decomposition of a complex containing

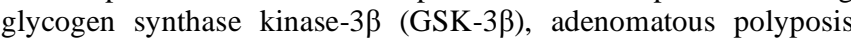
coli (APC) and axin. In the absence of Wnt signals, $\beta$-catenin is targeted for ubiquitin-mediated degradation. When released from the complex, $\beta$-catenin translocates to the nucleus and functions as a transcription cofactor of the $\mathrm{T}$ cell factor (TCF), activating responsive genes such as cyclin D1 and c-myc for example [23]. 


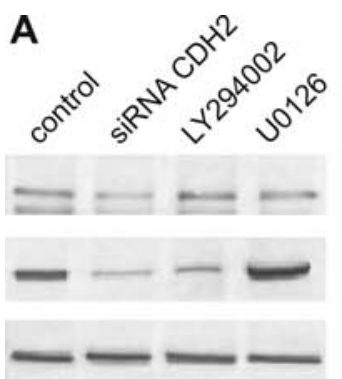

B Lu 1205

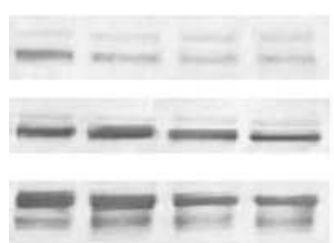

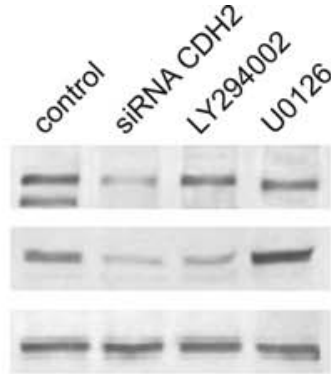

WM 793

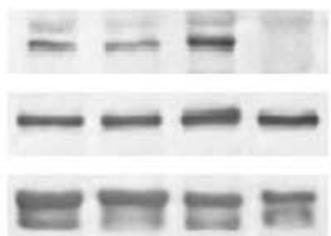

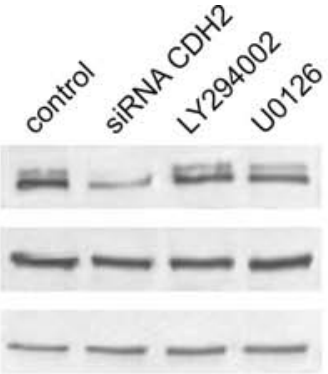

WM 115

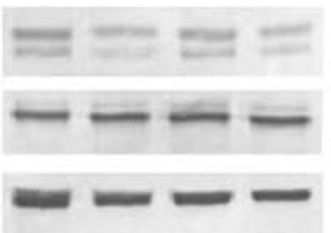

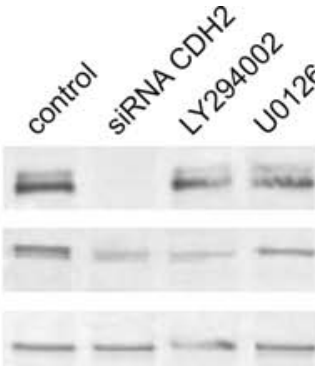

$\mathrm{N}$-cadherin $130 \mathrm{kDa}$

PAKT

$60 \mathrm{kDa}$

AKT

$60 \mathrm{kDa}$

WM 266-4

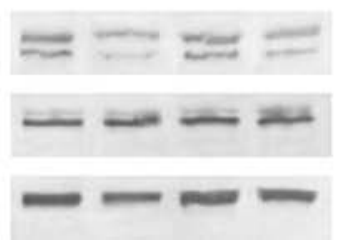

PERK

$42 / 44 \mathrm{kDa}$

ERK

$42 / 44 \mathrm{kDa}$

beta-actin $\quad 42 \mathrm{kDa}$

Fig. (2). The effect of N-cadherin silencing on (A) pAkt and (B) pERK 1/2 expression. Melanoma cells were transfected with non-silencing control siRNA or siRNA targeting the $\mathrm{N}$-cadherin $48 \mathrm{~h}$ after transfection: protein expression was analyzed by Western blot.

$\beta$-catenin is phosphorylated in its N-terminal domain by GSK$3 \beta$, which leads to its degradation by ubiquitination. GSK-3 $\beta$ constitutively phosphorylates $\beta$-catenin at S33, S37, and T41 (S33/37/T41) residues, triggering ubiquitinylation by a Cullin-1containing E3 ligase (also known as the SCF complex) before proteasomal degradation [24].

GSK-3 $\beta$ activity is inhibited by direct phosphorylation at S9. On the other hand, GSK- $3 \beta$ also has a tyrosine phosphorylation site, and tyrosine phosphorylation of GSK-3 $\beta$ (Y 216) increases its activity. siRNA mediated knock-down of $\mathrm{N}$-cadherin resulted in inactivation of GSK-3 $\beta$ because phosphorylation of GSK-3 $\beta$ on S9 was markedly higher, while phosphorylation of GSK-3 $\beta$ (Y 216) was markedly lower, compared with the control cells (Fig. 3). Ncadherin siRNA reduced the total level of $\beta$-catenin (Fig. 3). There was no significant difference between metastatic cell lines: Lu1205, WM266-4 and primary (VGP) melanoma cell lines (WM793, WM115). The appearance of phosphorylated $\beta$-catenin at (S33/37/T41) was noticed only in the Lu1205 cell line, while the decreased phosphorylation of $\beta$-catenin at S552 and S675 was observed after treatment with siRNA against $\mathrm{N}$-cadherin in all melanoma cell line (Fig. 3).

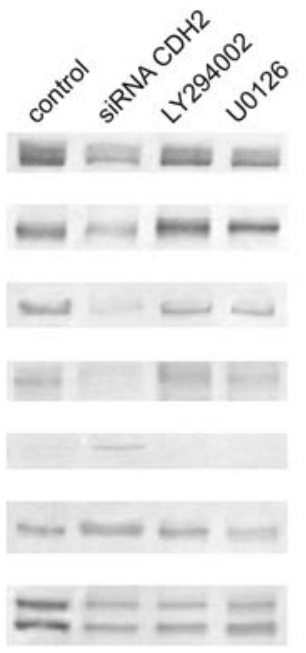

Lu 1205

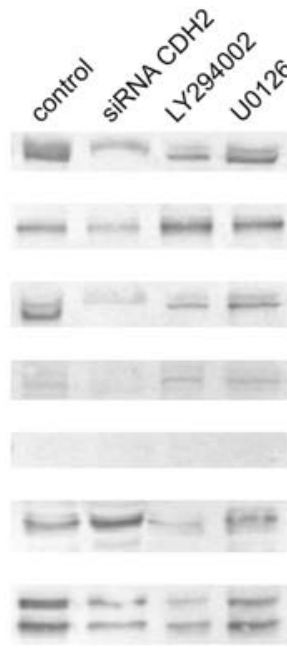

WM 793

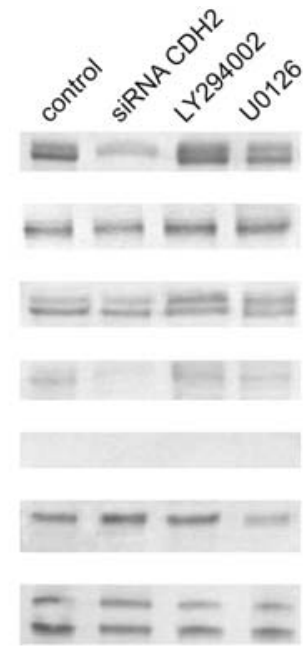

WM 115

\section{N-Cadherin Regulates Cell Proliferation}

To investigate if and how N-cadherin affects cell proliferation in melanoma cells, specific N-cadherin siRNA (siRNACDH2 \#1) that efficiently reduces $\mathrm{N}$-cadherin expression was used (Fig. 1).

Cell proliferation was studied with the BrdU ELISA (DNA synthesis) and crystal violet (number of cells) tests after $48-72 \mathrm{~h}$ CDH2 siRNA transfection.

The reduction of cell numbers after 48-72 h knock-down of $\mathrm{N}$ cadherin compared with control (non-specific siRNA), or nontreated cells was observed, while no significant differences in proliferations were shown after transfection with non-specific siRNA (control) or non-transfected cells (data not shown). We did not observe cytotoxicity effects after transfection of $\mathrm{N}$-cadherin siRNA (LDH activity in media of treated cells ranged from: 0.5-2.7 $\%)$.

$\mathrm{N}$-cadherin siRNA-transfected cells showed proliferation reduced by $50-70 \%$ when compared with control cells, regardless of the method used (Fig. 4). The effect was observed for metastatic cell lines WM793, Lu1205 and WM115 and WM266-4. However,

Fig. (3). The effect of N-cadherin silencing on total $\beta$-catenin and p-GSK expression. 
A

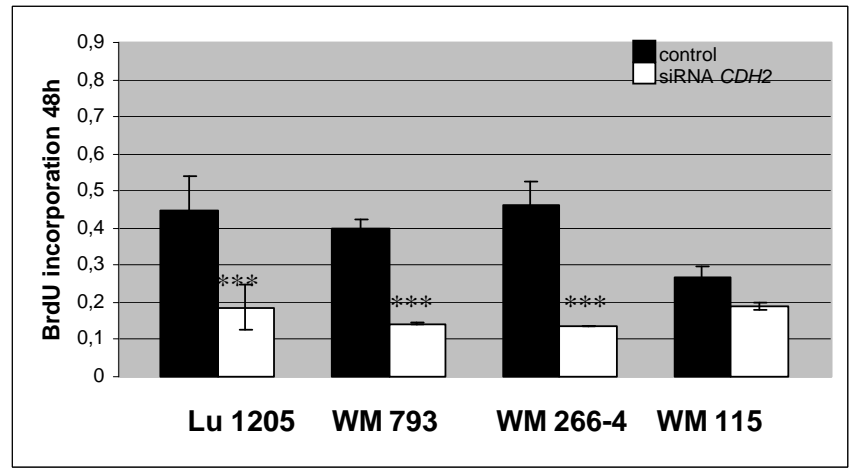

B

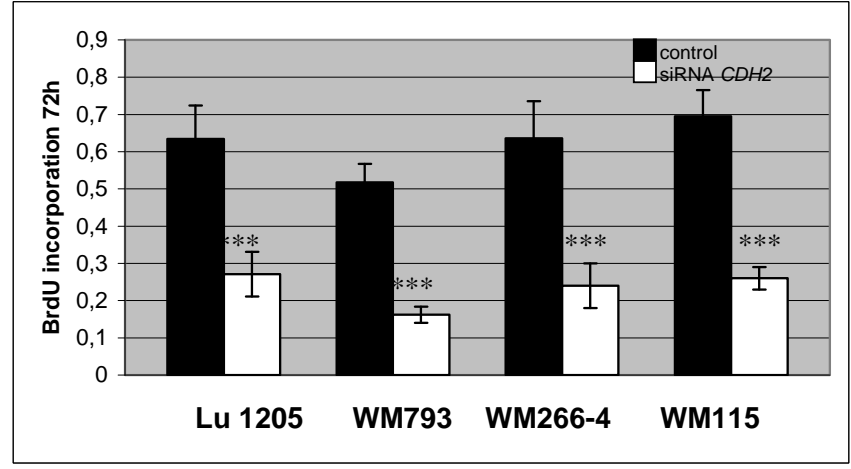

C

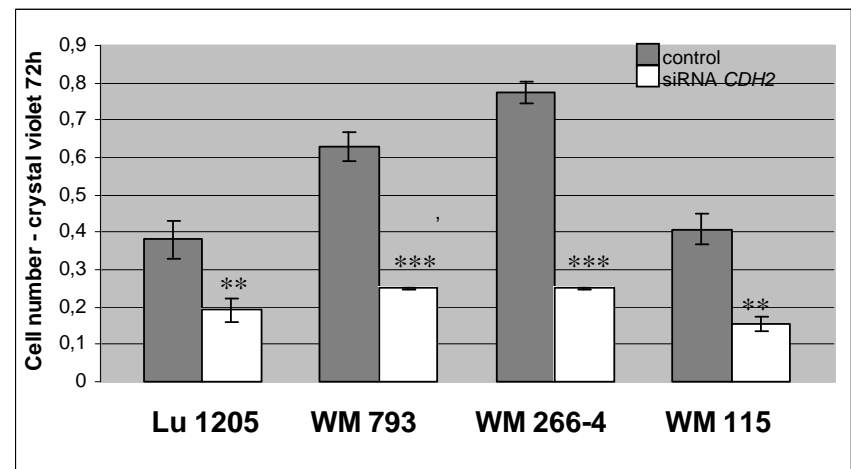

Fig. (4). DNA synthesis and proliferation of human melanoma cells.

Cells were treated for: $48 \mathrm{~h}(\mathbf{A})$ and $72 \mathrm{~h}(\mathbf{B})$ with CDH2 siRNA. Assays were performed with conventional methods: BrdU ELISA test for DNA synthesis in cells treated for $48 \mathrm{~h}(\mathbf{A})$ and $72 \mathrm{~h}$ (B) (Roche according to the manufacturer's protocol), as well as crystal violet test for proliferation (number of cells) after $72 \mathrm{~h}$ (C) CDH2 siRNA transfection. Cell proliferation is presented as absorbance units (A) at 540nm.

Values are expressed as mean \pm standard deviation in 8 wells in two independent experiments $* \mathrm{P}<0.05, * * \mathrm{P}<0.001, * * * \mathrm{P}<0.00001$

the most profound inhibition was noticed in case of WM793 and WM266-4, proliferation of which was inhibited after $72 \mathrm{~h}$ by: $68 \%$ $(\mathrm{p}<0.0001)$ and $62 \%(\mathrm{p}<0.0001)$ respectively (Fig. 4).

\section{N-Cadherin Regulates Cell Cycle}

Contact inhibited cells tend to accumulate at the G1 phase of the cell cycle. The relative level of phosphorylated $\mathrm{pRb}$ decreases, accompanied by accumulation of p27, over expression of wich causes cell cycle to arrest in G1.

$\mathrm{N}$-cadherin and $\beta$-catenin regulate melanoma cell proliferation throughout the inhibition of cell cycle proteins function. Western blot analysis showed that levels of cyclin D1 and D3, or cyclin dependent kinases CDK4, CDK6 were decreased in N-cadherin siRNA treated cells compared to the control. Decreased activity of

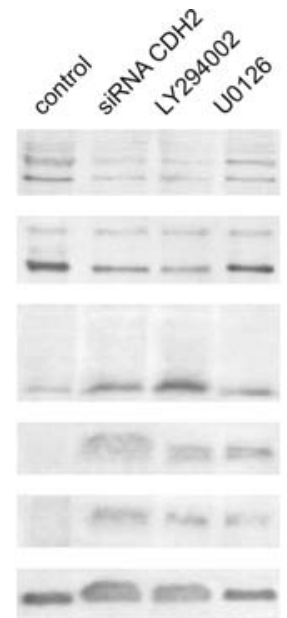

Lu 1205

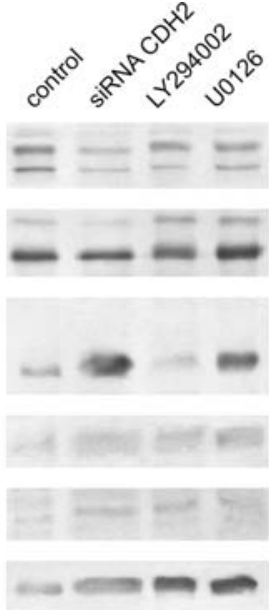

WM 793

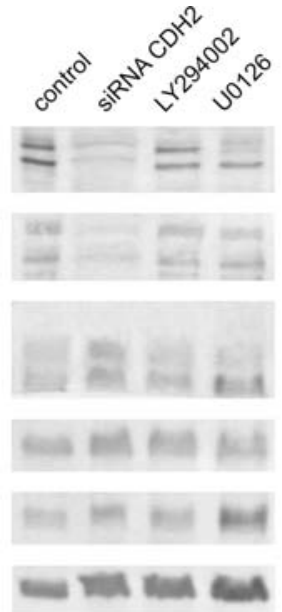

WM 115

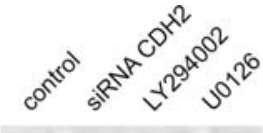

cyclin D1 $36 \mathrm{kDa}$ CDK4 $30 \mathrm{kDa}$

CDK6 $36 \mathrm{kDa}$ cyclin D3 $31 \mathrm{kDa}$

p21

$21 \mathrm{kDa}$

p16

$16 \mathrm{kDa}$

p27

$27 \mathrm{kDa}$

p15

$15 \mathrm{kDa}$

Fig. (5). The effect of $\mathrm{N}$-cadherin silencing on cell cycle protein expression in melanoma cells 
cyclin D3 and CDK6 after treatment with PI3K inhibitor LY294002 was also observed, while ERK1/2 kinase inhibitor - U0126 had no affect on the activity of cyclin D3, but led to a decreased level of cyclin D1 in WM115 and WM266-4 cell line (Fig. 5). Immunoblotting analysis revealed a 2-3-fold increase in the total levels of p15, p16, p21, and p27 in N-cadherin silencing cells. A similar affect was observed after application of both siRNA: $C D H 2 \# 1$ and $C D H 2 \# 2$, with the effect being stronger after using $C D H 2 \# 1$. We also noticed increased levels of these proteins after application of LY294002 and U1026 inhibitors. This indicated that the $\mathrm{N}$-cadherin mediated the entry of melanoma cells into S-phase of the cell cycle. In addition, after transfection with N-cadherin siRNAs, we observed down-regulation of pAKT and $\beta$-catenin in melanoma cells that caused inhibition of proliferation cells, associated with down-regulation of cyclin D1 and D3 proteins, and up-regulation of the cell cycle inhibitor p15, p16, p21 and p27.

\section{DISCUSSION}

The study showed that melanoma cells transfected with $\mathrm{N}$ cadherin specific siRNA decreased its expression at m-RNA and protein level. Transfection of all melanoma cell lines reduced the level of $\mathrm{N}$-cadherin successfully and transiently, resulting in proliferation inhibition and cell cycle arrest in G1 phase.

Cancer treatment often involves direct targeting of the enzymes essential for growth and proliferation of cancer cells [25]. Dynamic regulation of cadherin expression is strongly correlated with metastasis and progression of tumours. Many of the changes observed involve a key cell cycle step - the entry to S-phase. Indeed, this study found most of the cell cycle regulatory proteins, including cyclin D1, D3, CDK4, CDK6 and cell cycle inhibitors p15, p16, p21 and p27 to be deregulated.

Li K et al. (2009) [26] showed that knock-down of N-cadherin in ESCC cell line (EC9706) could arrest cell cycle at G0/G1 phase, induce cell apoptosis, reduce the invasiveness in vitro, and inhibit the tumor formation in vivo.

According to Smalley (2010) [25], the PI3K/AKT pathway is known to regulate proliferation of melanoma cells through the regulation of cell cycle entry at G1checkpoint and through the inactivation of GSK-3 $\beta$ leading to cyclin D1 deregulation [27].

The Wnt/ $\beta$-catenin signalling pathway plays essential role in cell proliferation and differentiation, and deregulated $\beta$-catenin protein levels lead to many types of human cancers.

Stabilized $\beta$-catenin translocates into the nucleus and complexes with members of the $\mathrm{T}$ cell factor (TCF)/lymphoid enhancer factor (LEF) family of transcription factors [28], leading to the activation of $\mathrm{Wnt} / \beta$-catenin responsive genes such as c-myc and cyclin D1 [23].

We observed a decrease in the total level of. $\beta$-catenin, and its decreased phosphorylation at S552 and S675 in all melanoma cell lines after their treatment with siRNA against $\mathrm{N}$-cadherin. According to Fang 2007 [29], AKT phosphorylates $\beta$-catenin at S552, and phosphorylation of $\beta$-catenin by AKT translocates $\beta$ catenin into the nucleus and increases its transcriptional activity promoting tumor cell invasion. AKT-dependent regulation of $\beta$ catenin plays a critical role in tumor invasion and development. Phosphorylation at S675 also induces $\beta$-catenin accumulation in the nucleus and increases its transcriptional activity [30]. Wnt signalling is known to effect cell growth and survival by several pathways in part by regulating ERK and PI3K signalling. Notably, the PI3K/AKT signalling cascade plays a key role in the control of cell proliferation and survival. We and others previously showed that PI3K/AKT is an important signalling pathway involved in the control of melanoma cell proliferation which, according to present results, seems to be significantly controlled by $\mathrm{N}$-cadherin.
The levels of cyclin D1and D3 or cyclin dependent kinases CDK4 and CDK6 were decreased after silencing of N-cadherin compared to control. Knock-down of N-cadherin reduced $\beta$-catenin transcriptional activity, which may be responsible for the reduction of cyclin D1 and D3 protein level. We have also observed decreased activity of cyclin D3 and CDK6 after treatment of cells with PI3K inhibitor LY294002, while inhibitor of ERK1/2 kinase U0126 had no effect on the activity of cyclin D3. Application of U0126, however, decreased the level of cyclin D1 in WM 115 and WM 266-4 cell lines.

Cell cycle arrest was shown to be accompanied by reduced phosphorylation of the retinoblastoma protein $\mathrm{Rb}$ as well as reduced expression of cyclin D3 and A in cell lines [31]. Cyclin D3 is the most widely expressed $\mathrm{D}$ type cyclin and its expression can be ratelimiting for G1/S transition. Levels of cyclin D1 and D3 are deregulated in malignant melanoma, cyclin D1 is up-regulated in melanoma cells through adhesion independent MEK-ERK1/2 signalling initiated by mutation of B-Raf [31], but Bhatt et al. (2005) [32] suggests that MEK-ERK1/2 signalling controls cyclin D1 level in melanoma cells in an adhesion-independent manner. Cyclin D3 expression is associated with poor clinical outcome in superficial melanoma [33]. According to Spofford 2006 [31], cyclin D3 expression was enhanced in a cell panel of human melanoma cell lines compared with melanocytes, and was regulated by fibronectin-mediated PI3-kinase/AKT signalling, but not MEKERK activity. Some authors have suggested that $\mathrm{N}$-cadherin enhances metastasis of breast tumours via increased ERK signalling and signal-regulated matrix metalloproteinase (MMP-9) production [22]. Our results show that silencing of N-cadherin, followed by reduction in pAkt expression, seems to indicate inhibition of cyclin D3 expression and involvement in cancer progression.

We also observed an increase in expression p15, p16, p21 and p27 proteins in cells treated with siRNA for N-cadherin. Increased levels of these proteins were also observed after application of LY294002 and U1026 inhibitors.

Studies of familiar malignant melanoma have demonstrated mutations in genes regulating G1/S transition including p16 and CDK4 [34]. Cyclin D1 is negative in nevi and expressed in $48 \%$ radial growth phase malignant melanomas [34]. Loss of p27 is required for the G1/S transition, as has been demonstrated in different experimental models. However over-expression of p27 has been found in subset of aggressive diffuse large cell lymphomas and Burkitt lymphomas. According to Florenes (2000) [33], vertical growth phase malignant melanoma shows simultaneous increase in proliferation and decrease in p27 protein expression (p 0.001) comparing with radial growth phase or benign lesions. Rössig et al., (2001) [35] showed that the AKT down-regulated p27 expression by inhibition of Forkhead transcription factor, and, on the other hand, stabilized cyclin D protein level via glycogen synthase kinase $3 \beta$ inhibition. Regulation of proliferation and cell cycle occurs with participation of AKT, and by reducing the level of p21 by phosphorylating and inactivating androgen receptor, transcription factor for p21 [36]. According to some authors the role of AKT to p21 is dependent on dual phosphorylation of p21. p21 phosphorylation at S146 results in increased p21 stability [37], while phosphorylation at T145 blocks nuclear translocation of p21 with further consequence of cytoplasm location of p21 as facilitation of the assembly and activity of the cyclin D-CDK4 complex, which promotes cell cycle progression through the $\mathrm{G}$ and into the S-phase [38, 35].

Our results suggest that knock-down of N-cadherin leads to increased level of the cell cycle inhibitors p15, p16, p21 and p27.

In conclusion, our findings demonstrate that $\mathrm{N}$-cadherin regulate melanoma cell proliferation via modulation of AKT, ERK and $\beta$-catenin signalling. Our investigations and literature data indicate the oncogenic role of $\mathrm{N}$-cadherin in the activation of AKT, 
ERK and $\beta$-catenin pathway. Inhibition of N-cadherin by siRNA reduces proliferation through a decrease in the activity of certain protein kinases which in turn leads to reduced activity of cyclins and increased activity of the cell cycle inhibitors. N-cadherin is likely to affect the regulation of proliferation and cell cycle by activating the AKT kinase pathway, but details of the mechanism are yet to be recognized.

\section{ACKNOWLEDGEMENTS}

This work was supported by a grant from Ministry of Science and Higher Education through Jagiellonian University Medical College K/ZDS/001470.

\section{REFERENCES}

[1] Freemont, A.J.; Hoyland, J.A. Cell adhesion molecules. J. Clin. Pathol., 1996, 49, 321M-330M

[2] Li, G.; Satyamoorthy, K.; Herlyn, M. Dynamic of cell interactions and communications during melanoma development. Crit. Rev. Oral Med., 2002, $13,62-70$

[3] Bozzo, J.; Dulsat, C. Therapeutic target for melanoma. Drug Future, 2008, 33(7), 615-631

[4] Sanders, D.S; Blessing, K.; Hassan, G.A.; Bruton, R.; Marsden, J. R. Jankowski, J. Alterations in cadherin and catenin expression during the biological progression of melanocytic tumours. Br. Med. J., 1999, 52, 151157

[5] Hirohashi, S. Inactivation of the E-cadherin-mediated cell adhesion system in human cancers. Am. J. Pathol., 1998, 153, 333-339.

[6] Hsu, M.; Meier, F.; Nesbit, M.; Hsu, J.; Belle, P.; Elder, D.; Herlyn, M. Ecadherin expression in melanoma cells restores keratinocyte-mediated growth control and down-regulates expression of invasion-related adhesion receptors. Am. J. Pathol., 2000, 156, 1515-1525

[7] Ciołczyk-Wierzbicka, D.; Amoresano, A.; Casbarra, A.; Hoja-Łukowicz, D.; Lityńska, A.; Laidler, P. The structure of the oligosaccharides of N-cadherin from human melanoma cell lines. Glycoconjugate J., 2003, 20 (7-8), 483-492

[8] Laidler, P.; Litynska, A.; Hoja-Łukowicz, D.; Łabędź, M.; Przybyło, M.; Ciołczyk-Wierzbicka, D.; Pocheć, E.; Trębacz, E.; Kremser, E. Characterization of glycosylation and adherent properties of melanoma cell lines. Cancer Immmunol. Immun., 2006, 55 (1), 112-118

[9] Hsu, M.; Wheelock, M.; Johnson, K.; Herlyn, M. Shift in cadherin profiles between human normal melanocytes and melanomas. Soc. Investig. Dermatol., 1996, 1, 188-194

[10] Jacobs, K.; Feys, L.; Vanhoecke, B.; Van Marck, V.; Bracke, M. P-cadherin expression reduces melanoma growth, invasion, and responsiveness to growth factors in nude mice. Eur J Cancer Prev., 2011, 20(3),207-16.

[11] Kuphal, S.; Martyn, A.C.; Pedley, J.; Crowther, L.M.; Bonazzi, V.F.; Parsons, P.G.; Bosserhoff, A.K.; Hayward, N.K.; Boyle, G.M. H-cadherin expression reduces invasion of malignant melanoma. Pigment Cell Melanoma Res., 2009, 22(3), 296-306

[12] Maret, D.; Gruzglin, E.; Sadr, M.S.; Siu, V.; Shan, W.; Koch, A.W.; Seidah, N.G.; Del Maestro, R.F., Colman D.R. Surface expression of precursor Ncadherin promotes tumor cell invasion. Neoplasia, 2010, 12(12),1066-80.

[13] Aplin, A.; Howe, A, Juliano R.L. Cell adhesion molecules, signal transduction and cell growth. Curr. Option Cell Biol., 1999, 11, 737-744

[14] Johnson, J. Cell adhesion molecules in the development and progression of malignant melanoma. Cancer and Metastasis Rev., 1999, 18, 345-357

[15] Hazan, R.B.; Phillips, G. R.; Qiao, R. F.; Norton, L.; Aaronson, S. A. Exogenous expression of $\mathrm{N}$-cadherin in breast cancer cell induces cell migration, invasion and metastasis. J Cell Biol., 2000, 148,779-790

[16] Derycke, L. D. M.; Bracke, M. E. N-cadherin in the spotlight of cell-cell adhesion, differentiation, embryogenesis, invasion and signaling. Int. J. Dev. Biol., 2004, 48, 463-476

[17] Williams, M.R.; Duncan, G.; Riach, R.A.; Webb, S.F. Acetylcholine receptors are coupled to mobilization of intracellular calcium in cultured human lens cell. Exp. Eye Res., 1993, 57, 381-384
[18] Christofori, G. New signals from the invasive front. Nature, 2006, 44(25), 444-450.

[19] Gil, D.; Ciołczyk-Wierzbicka, D.; Dulińska-Litewka, J.; Żwawa, K.; McCubrey, J.A.; Laidler, P. The mechanism of contribution of integrin linked kinase (ILK) to epithelial mesenchymal transition (ETM). Adv. Enzyme Regulation., 2011, 51,195-207

[20] Florenes, V.A.; Maelandsmo, G.M.; Kerbel, R.S. Protein expression of the cell-cycle inhibitor p27Kip1 in malignant melanoma: inverse correlation with disease-free survival. Am. J. Pathol., 1998, 153, 305-312

[21] Tran, NL.; Adams, DG.; Vaillancourt RR.; Heimark, R. Signal transduction from N-cadherin increases Bcl-2. J Biol. Chem., 2002, 277, 32905-32914

[22] Hulit, J.; Suyama, K.; Chung, S.; Keren, R.; Agiostratidou, G.; Shan, W.; Dong, X.; Williams, T.M.; Lisanti, M.P.; Knudsen, K.; Hazan, R. N-cadherin signalling potentiates tumor metastasis via enhanced extracellular signalregulated kinase activation. Cancer Res., 2007, 67(7), 3106-3116

[23] Tetsu, O.; McCormick, F. $\beta$-catenin regulates expression of cyclin D1 in colon carcinoma cells. Nature, 1999, 398, 422-426

[24] Wu, D.; Pan, W. GSK3 $\beta$ : multifaceted kinase in Wnt signalling. Trends in Biochem. Sci., 2010, 35(3), 161-168

[25] Smalley, K.S. Understanding melanoma signalling networks as the basis for molecular target therapy. J. Invest. Dermatol, 2010, 130, 28-37

[26] Li, K.; He, W.; Lin, N.; Wang, X.; Fan, Q. N-cadherin knock-down decreases invasiveness of oesophageal squamous cell carcinoma in vitro. World J. Gastroentero., 2009, 15(6), 697-704

[27] Diehl, JA.; Cheng, M.; Roussel, M.F.; Sherr C.J. Glycogen synthase kinase-3 beta regulates cyclin D1 proteolysis and subcellular localization. Genes Dev., 1998, 12(22), 3499-511

[28] Behrens, J. von Kries, JP.; Kuhl, M.; Bruhn, L.; Wedlich, D. Functional interaction of $\beta$-catenin with the transcription factor LEF-1. Nature, 1996, 382, 638-642

[29] Fang, D.; Hawke, D.; Zheng, Y.; Xia, Z.; Meisenhelder, J.; Nika, H.; Mills, G.; Kobayashi, R.; Hunter, T.; Lu, Z. Phosphorylation of beta -catenin by AKT promotes beta-catenin transcriptional activity. J. Biol. Chem., 2007, 282(15), 11221-11229

[30] Taurin, S.; Sandbo, N.; Qin, Y.; Browing, D.; Dulin N.O. Phosphorylation of beta-catenin by cyclic AMP-dependent protein kinase. J. Biol. Chem., 2006, 281(15), 9971-9976

[31] Spofford, L.S.; Abel, E.V.; Boisvert-Adamo, K.; Aplin, A.E. Cyclin D3 expression in melanoma cells is regulated by adhesion-dependent phosphatidylinositol 3-kinase signalling and contributes to G1-S progression. J. Biol. Chem., 2006, 281(35), 25644-51

[32] Bhatt, K V .; Spofford, L S.; Aram, G.; McMullen, M.; Pumiglia, K., Aplin, A E. Adhesion control of cyclin D1 and p27 ${ }^{\text {Kip1 }}$ levels is deregulated in melanoma cells through BRAF-MEK-ERK signalling Oncogene, 2005, 24 , 3459-3471

[33] Florenes, V.A.; Faye, R.S.; Maelandsmo, G.M. Levels of cyclin D1 and D3 in malignant melanoma: deregulated cyclin D3 expression is associated with poor clinical outcome in superficial melanoma. Clin. Cancer Res., 2000, 6, 3614-3620

[34] Soledad, R. A.; Orliz, P.; Pollan, M.; Perez-Gomez, B.; Sanchez, L.; Acuna, M. J.; Pajares, R.; Martinez-Tello, F. J.; Hortelano, C.M.; Piris, M.A. Rodrigues-Peralto, J. L. Progression in cutaneous malignant melanoma is associated with distinct expression profiles. A tissue microarray based study. Am. J. Pathol., 2004, 164, 193-203.

[35] Rössig, L.; Jadidi, A.S.; Urbich, C.; Badorff, C.; Zeiher, A.M. AktDependent Phosphorylation of p21 $1^{\mathrm{Cip} 1}$ Regulates PCNA Binding and Proliferation of Endothelial Cells Dimmeler S. Mol. Cell Biol., 2001, 21(16), 5644-5657

[36] Hanada, M.; Feng, J.; Hemmings, B. Structure, regulation and function of PKB/ATK - a major therapeutic target. BBA-Proteins Proteom., 2004, 1697(1-2), 11- 31

[37] Li, Y., Dowbenko, D., Lasky, LA. AKT/PKB phosphorylation of p21 Cip/WAF1 enhances protein stability of p21 ${ }^{\mathrm{Cip} / \mathrm{WAF} 1}$ and promotes cell survival. $J$. Biol. Chem., 2002, 277(13), 11352-11361

[38] Zhou, B.P.; Liao, Y.; Xia, W.; Spohn, B.; Lee, M.H.; Hung, M-Ch. Cytoplasmic localization of $\mathrm{p}^{\mathrm{Cip1} / \mathrm{WAF} 1}$ by Akt-induced phosphorylation in HER-2/neu-overexpressing cells. Nature Cell Biol., 2001, 3, 245 - 252 